\title{
Frequency distributions of magnetic storms and SI+SSC-derived records at Kakioka, Memambetsu, and Kanoya
}

\author{
Yasuhiro Minamoto ${ }^{1,3^{*}}$, Shigeru Fujita ${ }^{2}$ and Masahiro Hara ${ }^{1}$
}

\begin{abstract}
The Japan Meteorological Agency keeps records of geomagnetic phenomena observed at Kakioka (magnetic latitude, $27.47^{\circ}$ ), Memambetsu (magnetic latitude, $35.44^{\circ}$ ), and Kanoya (magnetic latitude, $22.00^{\circ}$ ). We used these records to examine the cumulative frequency distribution of magnetic storms, sudden impulses, and storm sudden commencements. The distributions of magnetic storms resemble the Gutenberg-Richter relation between earthquake frequency and magnitude used in seismology. The coefficients determined with the maximum likelihood method show that when the $\mathrm{H}$-range of a magnetic storm at Kakioka is doubled, the frequency of the magnetic storm is about one seventh, for example. Intense magnetic storms occur less frequently than calculated by the functions. This statistical analysis proves that there are no significant differences between slopes of the frequency distribution functions of the magnetic phenomena at Kakioka, Memambetsu, and Kanoya.
\end{abstract}

Keywords: Magnetic storm, Sudden impulses, Storm sudden commencements, Power law

\section{Introduction}

Solar-terrestrial environmental variations, that is, space weather, are monitored and forecast by using observations of the sun's surface, solar wind, and other solar phenomena. For example, solar flares are monitored by telescopes, and high-energy particle events are monitored by artificial satellites. Though such observations are essential to characterize events as they occur and to predict their effects, at present, only about 30 years of observations (i.e., three solar cycles) is available. Therefore, the data on these phenomena are insufficient to investigate the statistical properties of extreme solarterrestrial events. Sunspot numbers, which have been recorded for several hundred years, are a good index of long-term solar activity, but this index is not suitable for analyzing individual space weather events since there are many sunspots that are not linked to any geomagnetic phenomena. Geomagnetic phenomena such as magnetic storms, however, are discrete events that cause changes to

\footnotetext{
* Correspondence: minamoto.yasuhiro@nipr.ac.jp

'Kakioka Magnetic Observatory, Japan Meteorological Agency, 595 Kakioka,

Ishioka-shi, Ibaraki-ken 315-0116, Japan

${ }^{3}$ Present address: National Institute of Polar Research, 10-3, Midori-cho,

Tachikawa-shi, Tokyo 190-8518, Japan

Full list of author information is available at the end of the article
}

the solar-terrestrial environment, and records of such phenomena have been kept for as long as a hundred years. For example, Kataoka (2013) has estimated the probability of an extreme magnetic storm comparable in magnitude to the Carrington event occurring in the next decade by using the records of magnetic storms observed at Kakioka. Here, we investigated records of geomagnetic events observed at three magnetic observatories operated by the Japan Meteorological Agency (JMA): Kakioka, Memambetsu, and Kanoya. In this article, we provide the cumulative frequency distributions of sudden geomagnetic change phenomena, that is, sudden impulses (SI) and storm sudden commencements (SSC), and show latitude dependence of slopes of the frequency distribution functions in a low to middle magnetic latitude.

\section{Data}

JMA has published records of SSC, solar flare effects, SI, continuous pulsations, irregular pulsations, and geomagnetic storms observed at Kakioka (magnetic latitude, $27.47^{\circ}$ ), Memambetsu (magnetic latitude, $35.44^{\circ}$ ), and Kanoya (magnetic latitude, $22.00^{\circ}$ ) (Table 1). The periods of available records and the number of geomagnetic events recorded at each observatory are given in Table 2. Geomagnetic field observations have been carried out 
Table 1 Geographic and geomagnetic coordinates and altitudes of magnetic observatories operated by JMA (Kakioka Magnetic and Japan Meteorological 2013)

\begin{tabular}{lllllll}
\hline & IAGA code & ${\text { Latitude }(\mathrm{N})^{\mathrm{a}}}$ & ${\text { Longitude }(\mathrm{E})^{\mathrm{a}}}^{\circ}$ & Magnetic latitude $^{\mathrm{b}}$ & Magnetic longitude $^{\mathrm{b}}$ & Altitude $(\mathrm{m})^{\circ}$ \\
\hline Kakioka & KAK & $36^{\circ} 13^{\prime} 56^{\prime \prime}$ & $140^{\circ} 11^{\prime} 11^{\prime \prime}$ & $27.47^{\circ}$ & $209.23^{\circ}$ & 36 \\
Memambetsu & MMB & $43^{\circ} 54^{\prime} 36^{\prime \prime}$ & $144^{\circ} 11^{\prime} 19^{\prime \prime}$ & $35.44^{\circ}$ & $211.77^{\circ}$ & 42 \\
Kanoya & KNY & $31^{\circ} 25^{\prime} 27^{\prime \prime}$ & $130^{\circ} 52^{\prime} 48^{\prime \prime}$ & $22.00^{\circ}$ & $201.21^{\circ}$ & 107 \\
\hline
\end{tabular}

Japanese Geodetic Datum of 2000 (JGD2000)

${ }^{\mathrm{b}}$ Dipole coordinates for the International Geomagnetic Field, 11th generation (IGRF-11) of 2010.0; north pole, $80.08^{\circ} \mathrm{N}, 72.22^{\circ} \mathrm{W}$

continuously at Kakioka since 1913, and the data recorded on bromide paper and field notes had been transported to the Central Meteorological Observatory in Tokyo. On 1 September 1923, the records were destroyed by the fire caused by the Great Kanto earthquake (Minamoto 2012). Digital 1-min geomagnetic data at Kakioka, Memambetsu, and Kanoya have been available since 1976, 1985, and 1985, respectively. Before that, staff of observatories had measured lines on analog magnetograms and provided records of magnetic phenomena with a 1-min time resolution.

For the magnitude of a magnetic event, we adopted the $H$-range which is defined as the difference between the maximum and minimum values of $H$-component during the storm event. The definition is also used by Tsurutani et al. (2003). Records of 81 magnetic storms at Kakioka lack their ranges and those are not included in our analyses. Data of four magnetic storms which occurred in the 1940s include saturation of the instrument. The maximum values of $H$-range were $700,560,412$, and $368 \mathrm{nT}$. We include these events in our analyses.

SSC and SI are defined as a sudden commencement preceding a magnetic storm and an impulsive variation which is doubtful whether it is beginning a new storm, respectively, by the JMA (Kakioka Magnetic Observatory, 1987). Therefore, no SI has been recorded during magnetic storms by the JMA standard. Araki (2014) shows that the $H$-component amplitude of SC that occurred on 24 March 1940 is larger than $273 \mathrm{nT}$ at Kakioka. But we adopt $73 \mathrm{nT}$ as the $H$-component amplitude of SSC on that day, which is published by JMA. Records of SSC are included in the magnetic storm records at Kakioka, while recording of SI was started in September 1957, in accordance with a resolution of the International Association of Geomagnetism and Aeronomy (IAGA) at the General Assembly of the International Union of Geodesy and Geophysics at Toronto. The Symposium on
Rapid Magnetic Variations, held at Copenhagen in 1956, produced a list of geomagnetic phenomena about which observatories were sending monthly reports to the IAGA Committee of Rapid Magnetic Variations and Earth Currents. In these reports, the quality of SI and SSC records are designated as A, B, or C (Curto et al. 2007). Kurusu (1971) investigated magnetic events observed at Kakioka, Memambetsu, and Kanoya between July 1957 and December 1968 and developed criteria for determining the quality of the records, and JMA has since recorded the quality in conformity with those criteria. Records of magnetic phenomena classified as quality $\mathrm{C}$ include only the direction of change (positive or negative) of each parameter; the quantity of the variation is not recorded. Therefore, we limited our survey to event records of quality A or B.

\section{Relation between the magnitude of magnetic phenomena and their frequency}

For many kinds of natural phenomena, the magnitude of a phenomenon is related exponentially to its frequency of occurrence (Newman 2005). The relation between magnitude of an earthquake and the frequency of earthquakes of that magnitude follows a power law, which is known as the Gutenberg-Richter relation (Gutenberg and Richter 1944). We investigated whether a similar relationship exists between the magnitude of geomagnetic phenomena and their occurrence frequency.

In our results, the relation between cumulative frequency, where the frequency class width is 0.01 , and the magnitude of geomagnetic phenomena above a certain threshold magnitude follows a power law which resembles the Gutenberg-Richter relation (Figs. 1 and 2). However, fewer small events occur than are suggested by the power law, probably because small SI and SSC of quality $\mathrm{C}$ were not included. Such small phenomena were most likely to be neglected in the geomagnetic

Table 2 Recorded geomagnetic events at Kakioka, Memambetsu, and Kanoya

\begin{tabular}{llllll}
\hline & Magnetic storm & & & SI+SSC \\
\cline { 2 - 3 } \cline { 5 - 6 } & Observation period & Number of events & & Observation period & Number of events \\
\hline KAK & Feb. 1924-Dec. 2013 & 1942 & Feb. 1924-Dec. 2013 & 2875 \\
MMB & Jul. 1957-Dec. 2013 & 1228 & Jul. 1957-Dec. 2013 & 2437 \\
KNY & Jan. 1958-Dec. 2013 & 1179 & Jan. 1958-Dec. 2013 & 2286 \\
\hline
\end{tabular}



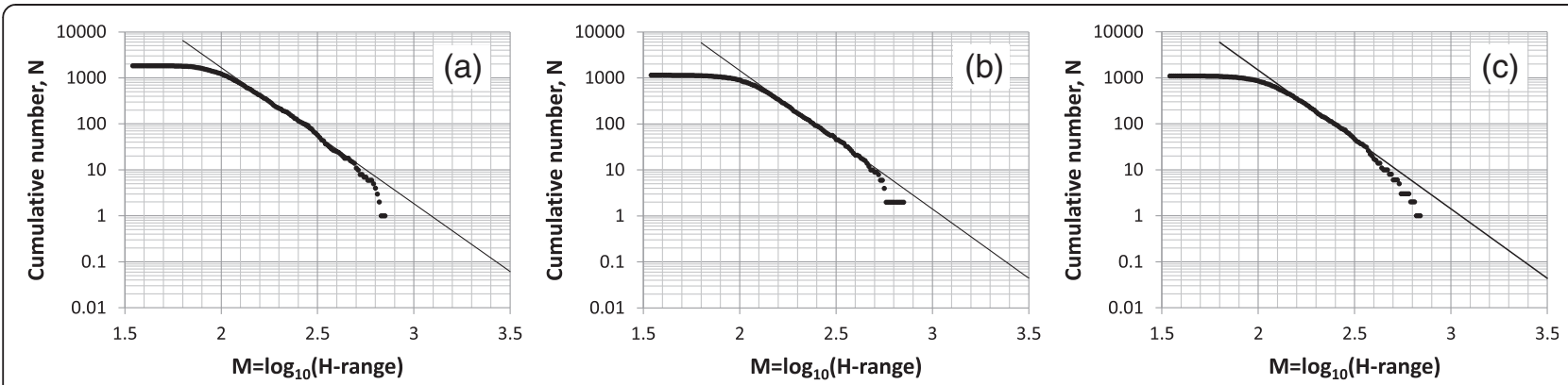

Fig. 1 Cumulative frequency distributions of the $H$-range of geomagnetic storms at a Kakioka (Feb. 1923 to Dec. 2013; $n=1849$ ), b Memambetsu (Feb. 1923 to Dec. 2013; $n=1150$ ), and c Kanoya (Feb. 1923 to Dec. 2013; $n=1096$ ). The straight line shows the estimated power law relation of the distribution. Intercepts of functions are rough estimates. The vertical axes show the cumulative number of occurrences and the horizontal axes show the event magnitude, indicated by the log 10 of the $\mathrm{H}$-range of the storm. $\mathrm{H}$-range is defined as the difference between the maximum and minimum values of the horizontal $(H)$ component of the geomagnetic field during the storm event

storm record. The number of occurrences of intense events is also smaller than the expected number. We discuss the reason for this in the "Summary and discussion" section.

The Gutenberg-Richter relation is expressed by the following equation:

$$
\log _{10} n(M)=a-b M
$$

where $M$ represents the magnitude of an earthquake and $n(M)$ represents the frequency distribution function of earthquakes of that magnitude. The coefficient $b$ which is the slope of the power law is characteristic for a group of earthquakes.

If the earthquakes being evaluated are arranged in order of magnitude and the magnitude of the $i$-th earthquake is denoted by $M_{i}$, then the value of $b$ is calculated as follows (Utsu 1965):

$$
b=\frac{0.4343 m}{\sum_{i=1}^{m} M_{i}-m M_{m}}
$$

where $m$ is the total number of earthquakes in the group and $M_{m}$ is the smallest magnitude of earthquakes in the group. If $M_{\text {ave }}$ is the average earthquake magnitude in the set of all earthquakes with magnitudes exceeding $M_{m}$, then the value of $b$ can be calculated by the following equation:

$$
b=\frac{0.4343}{M_{\mathrm{ave}}-M_{m}}
$$

In this study, we calculate the value of $b$ by using this function.

\section{Magnetic storms}

We plotted the cumulative number of magnetic storms at Kakioka against magnetic storm magnitude, adopting $\log _{10}(H$-range) as $M$ (Fig. 1$)$. The minimum magnitude, $M_{m}$, is estimated about 2.195 by examination of the plot. We determined that the $M_{m}$ value is within a range of 2.175 to 2.205 , which means that all magnetic storms with $H$-range larger than 150 to $160 \mathrm{nT}$, respectively, are recorded. We determined 31 values of $b$ from all magnetic storms corresponding to 31 values of $M_{m}$ which ranged from 2.175 to 2.205 in steps of 0.001 . The average and standard deviation of the $b$ value is 2.89 and 0.03 , respectively.
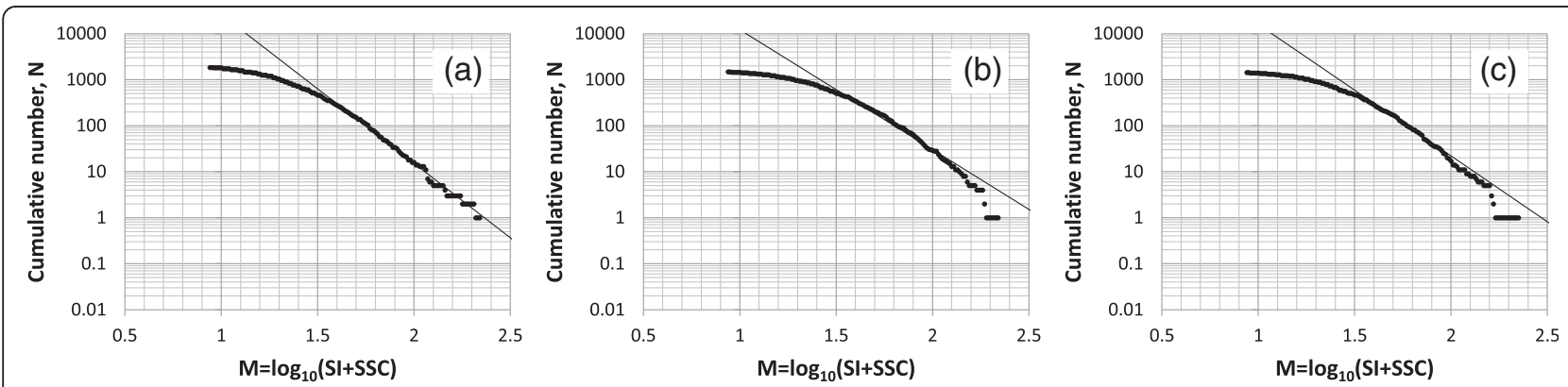

Fig. 2 Cumulative frequency distributions of geomagnetic SI+SSC at a Kakioka (Feb. 1923 to Dec. 2013; $n=1618$ ), b Memambetsu (Feb. 1923 to Dec. 2013; $n=1626$ ), and c Kanoya (Feb. 1923 to Dec. 2013; $n=1526$ ). The straight lines show the estimated power law relation for each distribution (see text). Intercepts of functions are rough estimates. The vertical axes show the cumulative number of occurrences and the horizontal axes show the event magnitude, indicated by log 10 of the sum of the horizontal components of the sudden impulse (SI) and the storm sudden commencement (SSC) of the storm event 
We observe that $M_{m}$ has common characteristics at the three observatories managed by JMA: Kakioka, Memambetsu, and Kanoya. Table 3 provides the average and standard deviation of $b$ values at those three observatories.

To investigate the significance of the difference between the observed distributions and the power law, we applied the Kolmogorov-Smirnov test for goodness of fit. From the sample, the cumulative distribution $S_{n}(x)$ is determined and plotted as a step function. The cumulative distribution $F(x)$ of the assumed population is also plotted on the same diagram.

The maximum difference between these two distributions

$$
D_{\max }=\max \left|F-S_{n}\right|
$$

provides the test statistic.

The value of $D \alpha$ corresponding to level of significance $\alpha$ is obtained from Table 4 in Kanji (2006). If $D_{\max }>D \alpha$, the null hypothesis that the sample came from the assumed population is rejected. We derived $D_{\max }$ and $D \alpha$ of $H$-range above estimated $M_{m}=2.195$ (Table 4). The number of intense storms is so small that they do not affect the value of $D_{\max }$. For the test statistic at Kakioka, $D_{\max }$ is 0.037 and the 1 per cent critical value $D \alpha$ is 0.080. The hypothesis was not rejected.

\section{SI and SSC}

We plotted the cumulative number of SI+SSC (i.e., the sum of SI and SSC) at each observatory against magnitude, adopting $\log _{10}(H$-amplitude) as $M$ (Fig. 2). The minimum magnitude, $M_{m}$, is estimated about 1.180. We determined that the $M_{m}$ value is within a range of 1.165 to 1.195 , which means that all events with SI+SSC larger than 15.1 to $16.4 \mathrm{nT}$, respectively, are recorded. We determined 31 values of $b$ for SI+SSC from all magnetic storms corresponding to 31 values of $M_{m}$ which ranged from 1.165 to 1.195 in steps of 0.001 for Kakioka, Memambetsu, and Kanoya. The average and standard deviation of $b$ values for the 31 values of $M_{m}$ are provided in Table 3.

Table 3 Average and standard deviation of $b$ values derived from 31 sets of $M_{m}$ which are stepwisely changed at Kakioka, Memambetsu, and Kanoya

\begin{tabular}{|c|c|c|c|c|c|c|}
\hline & \multicolumn{3}{|c|}{ Magnetic storm } & \multicolumn{3}{|c|}{$\underline{\mathrm{SI}+\mathrm{SSC}}$} \\
\hline & KAK & $\mathrm{MMB}$ & KNY & KAK & $\mathrm{MMB}$ & KNY \\
\hline Average & 2.89 & 2.94 & 2.95 & 1.18 & 1.17 & 1.18 \\
\hline std & 0.03 & 0.03 & 0.03 & 0.02 & 0.02 & 0.03 \\
\hline
\end{tabular}

Note that the $b$ values are the value of the slopes of the frequency distributions. $M_{m}$ refers to all recorded magnetic phenomena with magnitudes exceeding the specified values
Table 4 Test statistics and critical values for the one-sample test

\begin{tabular}{|c|c|c|c|c|c|c|c|}
\hline & & $D_{\max }$ & $N$ & $D a$ & & & \\
\hline & & & & $a=1 \%$ & $a=5 \%$ & $a=10 \%$ & $a=20 \%$ \\
\hline Storm & KAK & 0.0370 & 420 & 0.080 & 0.066 & 0.060 & 0.052 \\
\hline & MMB & 0.0191 & 340 & 0.088 & 0.074 & 0.066 & 0.058 \\
\hline & KNY & 0.0270 & 351 & 0.087 & 0.073 & 0.065 & 0.057 \\
\hline $\mathrm{SI}+\mathrm{SSC}$ & KAK & 0.1394 & 277 & 0.098 & 0.082 & 0.073 & 0.064 \\
\hline & $\mathrm{MMB}$ & 0.0992 & 346 & 0.088 & 0.073 & 0.066 & 0.058 \\
\hline & KNY & 0.1176 & 286 & 0.096 & 0.080 & 0.072 & 0.063 \\
\hline
\end{tabular}

$D_{\text {max }}$ is the maximum difference between the power law distribution and the observed distributions for two cases: "storm" which refers to the $\mathrm{H}$-range during the storms considered and "SI+SSC" which refers to the $H$-amplitude of the sum of SI and SSC. $N$ is the number of $H$-range values or $\mathrm{SI}$ SSC values which exceed the corresponding minimum values $M_{m}$. $D_{\text {max }}$ is derived from samples above $M_{m}$. The critical values Da corresponding to level of significance $a$ are from Kanji (2006)

Table 4 also provides $D_{\max }$ and $D \alpha$ of $H$-amplitude and SI+SSC values above estimated $M_{m}=1.180$. Even when $\alpha=20$ per cent, $D_{\max }>D \alpha$ at all the three observatories. Thus, the null hypothesis that the distributions from the three observatories are power law distributions may be rejected.

\section{Summary and discussion}

We showed that the frequency distribution of the $H$-range of magnetic storms resembles the Gutenberg-Richter relation between earthquake frequency and magnitude used in seismology. However, for SI+SSC, the hypothesis that the frequency distribution follows a power law is rejected by the Kolmogorov-Smirnov test. The frequency distributions of the $H$-range of magnetic storms are consistent with the frequency distributions of solar flares, which was shown to be a power law distribution in Crosby et al. (1993). Riley (2012) indicates that space weather events including flare intensity, coronal mass ejection speeds, and disturbance storm time (Dst) all exhibit power law distributions. Love et al. (2015) used weighted least squares and maximum likelihood methods to fit lognormal functions to Dst maxima for years 1957-2012.

The power law relation between the frequency and range of magnetic storms is expressed by the following equation:

$$
\log _{10} n(R)=a-b \log _{10}(R)
$$

where $R$ represents the $H$-range of a magnetic storm and $n(R)$ represents the frequency distribution function of magnetic storms of that $H$-range.

If value of $R$ is doubled, below is a variation of Eq. (5):

$$
\begin{aligned}
\log _{10} n(2 R) & =a-b \log _{10}(2 R) \\
& =a-b\left(\log _{10}(R)+\log _{10}(2)\right)
\end{aligned}
$$

The difference between Eq. (5) and Eq. (6) is 


$$
\log _{10} n(R)-\log _{10} n(2 R)=b \times \log _{10}(2)
$$

Given the calculated value of the slopes ( $b$ values) at Kakioka is 2.89 (in Table 3), the ratio of the frequency distribution functions is

$$
\begin{aligned}
& \log _{10} \frac{n(R)}{n(2 R)} \approx 0.860 \\
& n(R) / n(2 R) \approx 7.41
\end{aligned}
$$

Equation (9) suggests that if the $H$-range of a magnetic storm is doubled, the occurrence frequency decreases to about one seventh of the reference value.

However, intense phenomena plot below the line representing the power law on the plots, i.e., severe magnetic storms occur less frequently than we suggested above. One possible explanation is that the amplitude of magnetic disturbances has an upper limit. Vasyliūnas (2010) estimated that the upper limit for the negative value of the Dst index is -Dst - $2500 \mathrm{nT}$ by setting the effective plasma pressure equal to the magnetic pressure of the dipole field at the equator of each flux tube. Therefore, the power law expression is not appropriate to estimate the magnitude of extremely intense magnetic phenomena which could cause severe ground-induced currents.

Tsubouchi and Omura (2007) derived the expected maximum storm level from the probability density function of extreme storms and estimated Dst change of the maximum storm once in two centuries at $721.2 \pm 154.4 \mathrm{nT}$. Love et al. (2015) estimated extreme-event probabilities from fits of lognormal functions of Dst data for years 1957-2012.
But the confidence limits on forecasts remain wide due to few data.

We analyzed the 100 most intense storms among 1849 magnetic storms recorded at Kakioka and calculated that the $b$ value, i.e., the slope of the frequency distribution of the $\mathrm{H}$-range, is 3.81 which is significantly higher than the average value of 2.89 given in Table 3 . This is consistent with the cumulative frequency distribution of the 100 most intense geomagnetic storms shown in Fig. 3, which indicate a lower frequency of severe magnetic storms than predicted by the power law. Another possible approach is to analyze the time rate of change of the geomagnetic field or the induced electric field not only for events such as magnetic storms but for the entire period of observation.

No significant difference is seen in the values of the slopes of the frequency distributions of both $H$-range at the three observatories; in other words, magnetic storms have no latitude dependency on the slopes around Japan, between $22.0^{\circ}$ and $35.4^{\circ}$ in magnetic latitude. Rastogi (2006) shows that storm time variations of the $H$-range are largest at stations close to the magnetic equator and at the midday longitudes from data at stations in India between $-0.7^{\circ}$ and $45.2^{\circ}$ in magnetic latitude for the 17-18 November 1989 and the 20-21 February 1992 events. Pulkkinen et al. (2012) indicate that the maximum amplitude of the horizontal magnetic field drops across a boundary at about $40^{\circ}-60^{\circ}$ of geomagnetic latitude for the 13-15 March 1989 and the 29-31 October 2003 events. Further analyses are required to confirm the latitude dependency of the frequency distributions of geomagnetic phenomena.

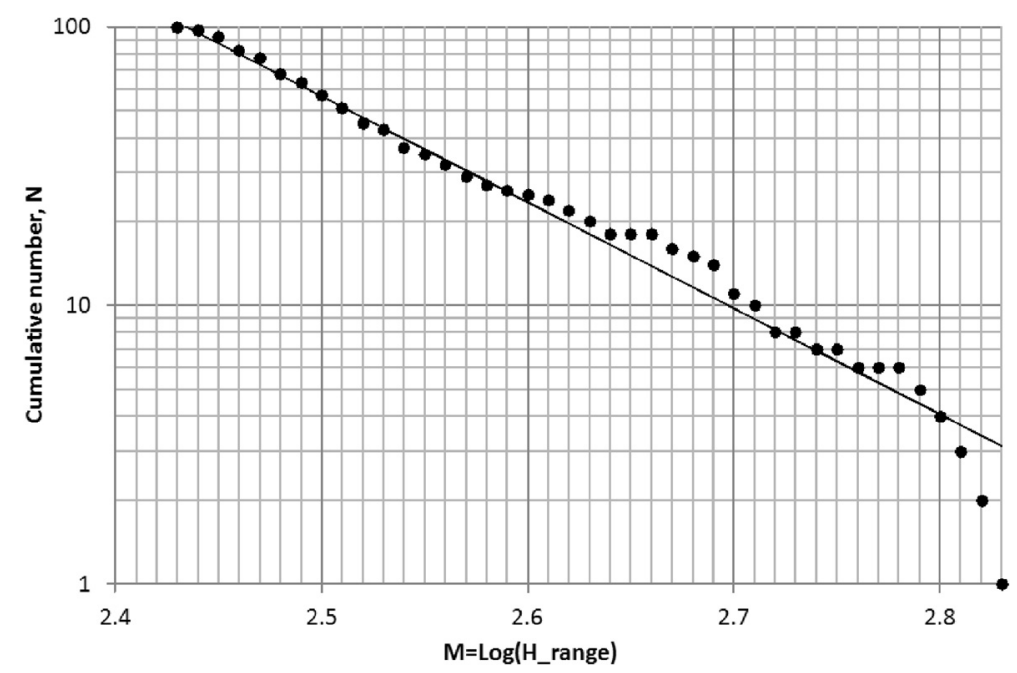

Fig. 3 Cumulative frequency distributions of 100 most intense geomagnetic storms at Kakioka. The vertical axes show the cumulative number of occurrences and the horizontal axes show the event magnitude, indicated by the log of the $\mathrm{H}$-range of the storm 


\section{Competing interests}

The authors declare that they have no competing interests.

\section{Authors' contributions}

All authors read and approved the final manuscript.

\section{Acknowledgements}

We are deeply grateful to Dr. Yuzo Ishikawa and Dr. Yutaka Hayashi, whose comments from a seismological viewpoint contributed enormously to our work. We thank the reviewers for careful reading of our manuscript and for giving useful comments.

\section{Author details}

${ }^{1}$ Kakioka Magnetic Observatory, Japan Meteorological Agency, 595 Kakioka, Ishioka-shi, Ibaraki-ken 315-0116, Japan. ${ }^{2}$ Meteorological College, Japan Meteorological Agency, 7-4-81, Asahi-cho, Kashiwa-shi, Chiba 277-0852, Japan. ${ }^{3}$ Present address: National Institute of Polar Research, 10-3, Midori-cho, Tachikawa-shi, Tokyo 190-8518, Japan.

Received: 24 December 2014 Accepted: 24 November 2015

Published online: 28 November 2015

\section{References}

Araki T (2014) Historically largest geomagnetic sudden commencement (SC) since 1868. Earth Planets Space 66:164

Crosby NB, Markus JA, Brian RD (1993) Frequency distributions and correlations of solar X-ray flare parameters. Solar Phys 143(2):275-299

Curto JJ, Cardus JO, Alberca LF, Blanch E (2007) Milestones of the IAGA International Service of Rapid Magnetic Variations and its contribution to geomagnetic field knowledge. Earth Planets Space 59:463-471

Gutenberg B, Richter CF (1944) Frequency of earthquakes in California. B Seismol Soc Am 34:185-188

Kakioka Magnetic Observatory (1987) Guideline of geomagnetic observation. Gijutsu Houkoku 26(special issue):183-190 (in Japanese)

Kakioka Magnetic Observatory, Japan Meteorological Agency (eds) (2013) Report of the Kakioka Magnetic Observatory, geomagnetism and geoelectricity-KakiokaMemambetsu_Kanoya_Chichijima_-2011. Kakioka Magnetic Observatory, Japan Meteorological Agency, Ishioka (CD-ROM)

Kanji GK (2006) The Kolmogorov-Smirnov test for goodness of fit. In: Kanji GK (ed) 100 Statistical Tests, 3rd edn. SAGE publications, London

Kataoka R (2013) Probability of occurrence of extreme magnetic storms. Space Weather 11:214-218. doi:10.1002/swe.20044

Kurusu K (1971) On geomagnetic storms, which occurred during the period from July 1957 to Dec 1968, and quality of SSC. Mem Kakioka Mag Obs 14(1):39-66 (In Japanese with English abstract)

Love JJ, Rigler EJ, Pulkkinen A, Riley P (2015) On the lognormality of historical magnetic storm intensity statistics: implications for extreme-event probabilities. Geophys Res Lett 42:6544-6553. doi:10.1002/2015GL064842

Minamoto Y (2012) Availability and access to data from Kakioka Magnetic Observatory, Japan. Data Sci J 12:G30-G35. doi:10.2481/dsjIAGA-10

Newman MEJ (2005) Power laws, Pareto distributions and Zipf's law. Contemporary Physics 46:323-351. doi:10.1080/00107510500052444

Pulkkinen A, Bernabeu E, Eichner J, Beggan C, Thomson AWP (2012) Generation of 100-year geomagnetically induced current scenarios. Space Weather 10:4. doi:10.1029/2011SW000750

Rastogi RG (2006) Magnetic storm effects at equatorial electrojet stations. Earth Planets Space 58:645-657

Riley P (2012) On the probability of occurrence of extreme space weather events. Space Weather 10:S02012. doi:10.1029/2011SW000734

Tsubouchi K, Omura Y (2007) Long-term occurrence probabilities of intense geomagnetic storm events. Space Weather 5:S12003. doi:10.1029/2007SW000329

Tsurutani BT, Gonzalez WD, Lakhina GS, Alex S (2003) The extreme magnetic storm of 1-2 September 1859. J Geophys Res 108:1268. doi:10.1029/2002JA009504,A7

Utsu T (1965) A method for determining the value of $b$ in a formula log $n=a-M$ showing the magnitude-frequency relation for earthquakes. Geophys B Hokkaido Univ 13:99-103 (In Japanese with English abstract)

Vasyliūnas VM (2010) The largest imaginable magnetic storm. J Atmos Sol-Terr Phys 73(11-12):1444-1446

\section{Submit your manuscript to a SpringerOpen ${ }^{\odot}$ journal and benefit from:}

- Convenient online submission

- Rigorous peer review

- Immediate publication on acceptance

- Open access: articles freely available online

- High visibility within the field

- Retaining the copyright to your article

Submit your next manuscript at $>$ springeropen.com 